TABLE I.

Number of New Groups of Sun-spots observed each Year. The Observations from 1826 to 1863 were made by Hofrath Schwabe, the others were made at the Kew Observatory.

\begin{tabular}{|c|c|c|c|c|c|}
\hline Year: & $\begin{array}{c}\text { No, of new } \\
\text { groups. }\end{array}$ & Year. & $\begin{array}{c}\text { No. of new } \\
\text { groups. }\end{array}$ & Year. & $\begin{array}{c}\text { No. of ne } \\
\text { groups. }\end{array}$ \\
\hline 1826 & 118 & 1842 & 68 & 1858 & I 88 \\
\hline 1827 & 161 & 1843 & 34 & 1859 & 205 \\
\hline 1828 & 225 & 1844 & $5^{2}$ & 1860 & 210 \\
\hline 1829 & 199 & 1845 & II 4 & 1861 & 204 \\
\hline 1830 & 190 & 1846 & I 57 & 1862 & 160 \\
\hline $183 \mathrm{I}$ & $I_{49}$ & 1847 & 257 & 1863 & I 24 \\
\hline 1832 & 84 & 1848 & 330 & I 864 & 113 \\
\hline 1833 & 33 & 1849 & 238 & I 865 & 93 \\
\hline 1834 & $5 \mathrm{I}$ & 1850 & 186 & 1866 & 45 \\
\hline 1835 & 173 & I85I & 151 & 1867 & 17 \\
\hline 1836 & 272 & 1852 & 125 & 1868 & 115 \\
\hline 1837 & 333 & II 53 & 9 I & 1869 & 224 \\
\hline 1838 & 282 & 1854 & 67 & 1870 & 403 \\
\hline 1830 & 162 & 1855 & 38 & 1871 & 271 \\
\hline 1840 & 152 & $1850^{\circ}$ & 34 & 1872 & 186 \\
\hline 1841 & 102 & 1857 & 98 & & \\
\hline
\end{tabular}

From which it appears that $1828,1837,1848,1860$, and 1870 were years of maximum, while $1833,1843,1856$, and I 867 were years of minimum sun-spot frequency.

While Schwabe was observing the sun with praiseworthy regularity, Sir E. Sabine was likewise observing the magnetism of the earth. A freely suspended magnetic needle is usually thought to be very constant as to the direction in which it points, and this is no doubt quite true as far as large fluctuations are concerned. Nevertheless, between certain small limits it is always in motion-it has, for instance, a well understood oscillation depending upon the hour of the day, besides which it is also liable to irregular fluctuations that occur abruptly. Now Sabine perceived that these abrupt and spasmodical affections of the needle were most frequent in years when sun-spots were most frequent; and, furthermore, inasmuch as these fluctuations of the magnet are almost invariably accompanied with displays of the aurora borealis, he came to the conclusion that auroral displays occur most frequently in years of maximum sun spots. Our readers will no doubt remember the brilliant auroræ of 1870 , which was likewise (see Table 1) a year of maximum sun-spot frequency.

What we have said refers to the spasmodical affections of the needle, but its diurnal oscillations are not less dependent on the state of the sun's surface.

Here also we have a maximum amount of fluctuation in years of maximum sun-spot frequency.

This near relation between sun-spots on the one hand, and magnetic oscillations and auroral displays on the other, is exhibited in Diagram A, which has been compiled by Prof. Loomis, the well-known American meteorologist.

Close and striking as is the relation between these three associated phenomena exhibited in the above diagram, the intimacy of this connection may be rendered even more obvious if we confine ourselves to such observations of the solar surface and of magnetic fluctuations as have been made with the greatest possible accuracy.

For this purpose Schwabe's eye-observations are not precise enough, and we must; as far as sun-spots are concerned, make use of some very accurate measurements of the solar spotted area made at Redhil] by the late R. C Carrington, along with the results deduced from the solar photographs taken at the Kew Observatory, under the superintendence of Mr. Warren De La Rue.

Again, as far as magnetic observations are concerned, let us employ the results derived from the self-recording magnetographs at the Kew Observatory.
Furthermore, in order to equalise oscillations of short period, let us plot a solar curve, each point of which represents the mean of nine months' sun-spot observations, and alongside of it a magnetic curve, each point of which similarly represents the mean of nine months' magnetic observations.

A comparison of this kind has been made by the writer of these remarks, the results of which were recently communicated by him to the Royal Society. These results are embodied in Diagram $B$, in which accurate sun-spot observations are compared with Kew declination ranges, that is to say, with the diurnal oscillations of a magnetic needle, freely suspended at the Kew Observatory.

A comparison of the two curves given above will show us that almost every prominent fluctuation of the sunspot curve is represented in the magnetic curve, similar letters being employed to denote what appears to be corresponding fluctuations.

There is, however, a greater want of similarity for that part of the solar curve which is dotted, but this represents the results of eye-observations taken by Hofrath Schwabe, while the more accurate Kew photoheliograph was unfortunately out of action.

It will be perceived that the magnetic fluctuations invariably follow after or lag behind the corresponding solar fluctuations in point of time, the mean amount of this lagging being probably six months. We may therefore conclude from these comparisons that there is a very close and intimate relation between the physical condition of the sun's surface and the diurnal oscillations of the magnetic needle freely suspended at the Kew Observatory, and also that the former is probably the cause of which the latter is the effect, or at least that the magnetic change lags behind the corresponding solar phenomencn in point of time.

BALFOUR STEWART

(To be continued.)

\section{THE FRENCH TRANSIT MEDAL}

WE recently announced that the Paris Academy of Sciences had presented an appropriate medal to those Frenchmen who were engaged in observing the recent transit of Venus, as well as to all the members of the Academy. By the kindness of the editor of $L a$

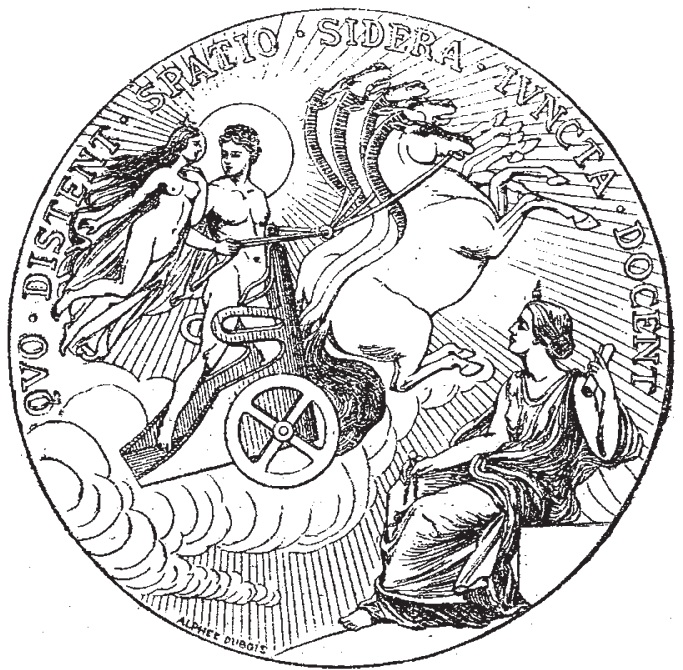

Nature we are able to give an illustration of the principal face of this medal, the design being that of the artist $M$. Alphée Dubois. It will be seen that the artist has had recourse to mythology to represent under a graceful form the important astronomical phenomenon. Venus, in the 
simple costume of the goddesses, passes before the car of Apollo, the god of the sun, while Science observes the phenomenon on the earth and records the results. The legend is the composition of a member of the Academy of Inscriptions. On the obverse of the medal is the following inscription :--

\section{INSTITUT DE FRANCE}

ACADÉMIE DES SCIENCES

Passage De Vénus Sur Le Solerl

$$
\text { 8-9 DECEMPER, I874. }
$$

\section{THE EFFECT OF INAUDIBLE VIBRATIONS} UPON SENSITIVE FLAMES

DURING a recent visit to Birmingham my friend and host, Mr. Lawson Tait, showed me some interesting experiments with one of Mr. Galton's whistles, capable of yielding vibrations beyond the limit of hearing. This led to the suggestion of trying a sensitive flame with these whistles, and in fulfilment of my promise to select and send to Mr. Tait a burner sensitive to very high notes, I was yesterday led to make the following experiment, the result of which is, I believe, new, and I think sufficiently interesting to put on record. A sensitive flame was obtained just two feet high when undisturbed, but shrinking down to seven inches under the influence of the feeblest hiss or the clink of two coins. Adjusting the Galton whistle, which Mr. Tait lent me, so as to yield its lowest note, little effect was produced on the flame; a shrill dog. whistle produced a slight forking of the flame, but that was all. Raising the pitch of the Galton whistle, the flame became more and more agitated, until, when $I$ had nearly reached the upper limit of audibility of my left ear, and had gone quite beyond the limit of my right ear, the flame was still more violently affected. Raising the pitch still higher, until I quite ceased to hear any sound, and until several friends could likewise detect no sound, even when close to the whistle, I was astonished to observe the profound effect produced upon the flame. At every inaudible puff of the whistle the flarne fell fully sixteen inches, and burst forth into its characteristic roar, at the same time losing its luminosity, and when viewed in a moving mirror, presenting a multitude of ragged images, with torn sides and flickering tongues-indicating a state of rapid, complex, and vigorous vibration.

Nor was this effect sensibly diminished by a distance of some twenty feet from the flame. Placing the flame at one end of the large lecture theatre of this college, and blowing the whistle at the furthest point away, a distance at least of fifty feet and more than thirty feet above the flame, still the effect produced was very pronounced. There can hardly be a more striking experiment. A single silent and gentle puff of air sent from the lips through the whistle, nothing whatever to be heard, and yet fifty feet away an effect produced that might readily be seen by thousands of people.

The extreme smallness of the amount of motion actually concerned in producing this great change in the aspect of the flame is evident. For the inaudible vibrations, having at their origin but a small amplitude, gave rise to a spherical air-wave, ${ }^{1}$ which at a radius of fifty feet-and with the vast enfeeblement due to this distance -knocked down a two-foot flame, though the surface acted upon had an area of less than a square inch-for it is only the root of the flame that picks up the wave motion. Of course everything depends upon the delicately-poised state into which the flame has previously to be brought. It then, like a resonant jar, enters into a state of vibration which appears to be synchronous with the note producing the effect. By this means it may be possible, with the aid of a mirror moving at a known speed, to determine the

I I have no doubt a similar result would attend an experiment made in the open air, if the air were still enough to allow it to be made. vibration number of these high notes, and thus with greater exactitude fix the upper limit of hearing.

The flame giving the effect here described was produced by coal gas contained in a holder under a pressure of ten inches of water, and issuing from a steatite jet having a circular orifice $0^{\circ} 04$ inch in diameter. ${ }^{1}$

\section{W. F. BARRETT}

\section{SOUND-VIBRATIONS OF SOAP-FILM MEMBR.ANES}

THE vibration-forms of membranes agitated by their fundamental and upper tones, have usually been studied by means of thin bladder or india-rubber stretched on a ring or frame (see Helmholtz "Sensations of Tone," chaps. iii. and v.; Pisko, "Die Neueren Apparate der Akustik," p. 75). While I was lately trying with Mr. R. Knight the capabilities of various membranes of taking impressions from vocal sounds for phonautographic purposes, the idea occurred of using soap-film. This was at once carried into effect by dipping the end of a lampchimney into some soap-solution, strengthened in the usual way with glycerine and a little gelatine. On singing near the open end of the chimney, the series of forms belonging to the various notes became plainly visible, those produced by the upper tones being as it were engine-turned in their complex symmetry, in a way to which the sand-lines on so coarse a material as caoutchouc can bear no comparison. To exhibit these forms at a popular lecture here last night, the light of an oxyhydrogen magic lantern was simply reflected off the vibrating film upon the screen in a disc of some three feet in diameter, so as to show its pat terns on a large scale when set in movement by talking, singing, and playing a cornet in its neighbourhood. The effects were of singular ciearness and beauty. To lec iurers who may use this new and easy means of making the more complex sound-vibrations appreciable by the eye, I would mention that by slightly thinning the soapsolution, and adding a few drops of ammonia, they may obtain a film more free from interference-colours, so as to display the vibration-figures on an almost clear ground. But if this is done, the thicker mixture should be used afterwards, for the gorgeous scenic effect of the masses of prismatic colour whirled hither and thither by the musical vibrations.

Wellington, Somerset, April 20

EDWARD B. TYLOR

\section{THE OTHEOSCOPE ${ }^{2}$}

I COMMUNICATED to the Royal Society in November last, an account of some radiometers which I had made with the object of putting to experimental proof the "molecular pressure" theory of: the repulsion resulting from radiation. Continuing these researches I have constructed other instruments, in which a movable fly is caused to rotate by the molecular pressure generated on fixed parts of the apparatus.

In the radiometer, the surface which produces the molecular disturbance is mounted on a fly, and is driven backwards by the excess of pressure between it and the sides of the containing vessel. Regarding the radiometer as a heat-engine, it is seen to be imperfect in many respects. The black or driving surface, corresponding to the heater of the engine, being also part of the moving fly, is restricted as to weight, material, and area of surface. It must be of the lightest possible construction, or

I The conditions necessary for obtaining the utmost sensitiveness of the flame are described in an article I published on the subject in the Popular

Science Review for April, 1867.
z On Repulsion Resulting from Radiation. Preliminary note on the Otheoscope, by William Crookes, F.R.S., \&c. Read before the Royal Society, April 26, 1877 . 